elicit the bleeding. ${ }^{1516}$ In very immature infants severe birth asphyxia may cause early death from bleeding, and recurrent apnoea or possibly infection may also be associated, perhaps through some common stress such as metabolic acidosis. Wigglesworth ${ }^{15} 16$ believes that the condition develops in more mature infants only in the presence of hyaline membrane disease, particularly when they are given intensive alkaline buffer treatment.

Prompt attention should be given to immature infants at birth and during episodes of recurrent apnoea. Nevertheless, at the same time a minimum of handling by nursing and medical staff avoiding injudicious treatment with alkali, and prevention of infection might go some way to reducing bleeding as an important cause of death.

\footnotetext{
Bleyer, W A, Hakami, N, and Shepard, T H, fournal of Pediatrics, 1971, 79, 838.

Chamberlain, R, et al, British Births, 1970, vol 1, The First Week of Life, pp 241 and 246. London, Heinemann Medical, 1975.

3 Glader, B E, and Buchanan, G R, Pediatrics, 1976, 58, 548

- Human Blood Coagulation, Haemostasis and Thrombosis, ed R Biggs, p 299. Oxford, Blackwell, 1972 .

Davies, P A, et al, Medical Care of Newborn Babies. Clinics in Developmental Medicine 44 45, p 206. London, Heinemann Medical, 1972.

${ }^{6}$ Hathaway, W E, Clinics in Perinatology, 1975, 2, 83.

' Chessells, J M, and Wigglesworth, J S, Archives of Disease in Childhood, 1970, 45, 539.

* Chessells, J M, and Wigglesworth, J S, Archives of Disease in Childhood, $1971,46,38$.

${ }^{9}$ Henriksson, P, and Ekelund, H, Acta Paediatrica Scandinavica, 1975, 64, 327.

" Gottuso, M A, Williams, M L, and Oski, F A, fournal of Pediatrics, 1976, 89, 279.

"Keenan, W J, Jewett, I, and Glueck, H I, American fournal of Diseases of Children, 1971, 121, 271.

12. Cole, V A, et al, Pediatrics, 1973, 51, 175.

${ }^{13}$ Hambleton, G, and Wigglesworth, J S, Archives of Disease in Childhood, 1976, 51, 651 .

14 Chu, J, et al, Pediatrics, 1967, 40, 709

15 Wigglesworth, J S, et al, Archives of Disease in Childhood, 1976, 51, 755.
}

${ }^{16}$ Wigglesworth, J S, et al, Archives of Disease in Childhood, 1977, 52, 447.

\section{A vaccine against gonorrhoea?}

Gonorrhoea has become one of the most common infectious diseases, but measures for its control are still based on providing facilities for diagnosis and treatment, tracing contacts of infected patients, and health education. Other major infections have been subdued by the development and distribution of a vaccine giving effective artificial immunity. What are the prospects of such an approach with gonorrhoea?

At first sight the chances might not seem too hopeful. The natural disease does not evoke a very strong immune response and does not confer immunity to reinfection. Nevertheless, the resurgence of gonorrhoea has stimulated research on the immunochemistry of the gonococcus and on how it initiates infection. The results of this work suggest that development of a vaccine may eventually be possible.

When attempts were made to immunise men with autolysed gonococci ${ }^{1}$ an immune response was stimulated in volunteers, but it gave no protection in a small field trial. Clearly, therefore, we need animal models to study the production of protective antibodies. Chimpanzees can be infected with gonococci via the urethra, producing an infection similar to that in man, and if this is allowed to run its natural course without treatment the animals become refractory to reinfection with the same, but not a different, strain. Arko et $a l^{2}$ found that immunisation of chimpanzees with gonococci treated with formalin protected against challenge-but again only from the immunising but not other strains. ${ }^{2}$ The interaction between gonococci and the host's immune response has also been studied in tissue fluid accumulating in chambers implanted subcutaneously in guinea-pigs. With this system Arko et $a l^{3}$ found that immunisation not only increased resistance to establishing infection in the chambers by the same strain but that some gonocococci also partially protected against infection with other strains. Nevertheless, the antigenic heterogeneity of gonococci is likely to be one of the obstacles to developing a vaccine, and we need further information on the diversity and geographical distribution of antigenic types.

The outer surface structures of the gonococcus seem likely to be an important target for any immune response produced by immunisation. Three components of this complex have been identified and methods developed for their isolation and purification. These are lipopolysaccharides, an outer membrane protein complex, and the pili or fimbriae. An antibody reacting with lipopolysaccharide is produced during infection ${ }^{4}$ and is bactericidal.5 The outer membrane protein complex contains determinants for type specificity, and so far 16 different serotypes have been identified. ${ }^{6}$ In experiments with the guinea-pig chamber model Buchanan and $\mathrm{Arko}^{7}$ found that immunisation with $400 \mu \mathrm{g}$ of purified outer membrane protein produced protection (related to the strain used) comparable with that given by $200 \mathrm{mg}$ of formolised whole gonococci. ${ }^{?}$

When first isolated in vitro, gonococci possess pili, fine filaments extending from their outer surface. These pili are associated with virulence: present in freshly isolated cocci, they are absent from the avirulent colony types characteristic of old laboratory strains, though virulence can be maintained for long periods by selective subculture. ${ }^{8}$ When studied in vitro pilated gonococci show greater adherence to epithelial and other cells than non-pilated organisms; pili are thought to help the gonococcus make its initial lodgment on a mucosal surface by anchoring it to epithelial cells. Nevertheless, electronmicroscopic studies of gonococci in urethral pus have shown that most of the cocci are not pilated. ${ }^{9}$ Antibody reacting with pili appears during infection, ${ }^{10}$ and in vitro inhibits the attachment of gonococci to epithelial cells. ${ }^{11}$ Pili from different strains have been found to differ antigenically. ${ }^{1213}$ Finally, recent reports suggest that capsules are present on freshly isolated gonococci ${ }^{14} 1.5$; their nature has not yet been studied, but if the capsular substance can be isolated and characterised it will give another source of material for trial as a vaccine.

An ideal vaccine for use against gonorrhoea should provide a solid and lasting protection against infection with the widest possible antigenic spectrum of gonococci. Production of a partial immunity-sufficient to prevent overt infection while allowing the recipient to harbour gonococci-would be especially dangerous. The transition from experimental studies of a vaccine in animals to its use in man will eventually require controlled field trials in informed volunteer groups; the organisation and evaluation of such trials will certainly not be easy. If they showed a vaccine to be protective, how could it best be used in practice? Should it be given on request or restricted to selected patients in high risk groups? These are but some of the ethical and practical problems which a vaccine against gonorrhoea will pose.

1 Greenberg, L, et al, Bulletin of the World Health Organisation, 1971, 45, 531. 
${ }^{2}$ Arko, R J, et al, fournal of Infectious Diseases, 1974, 130, 160.

${ }^{3}$ Arko, R J, et al, Infection and Immunity, 1976, 14, 1293.

${ }^{4}$ Watt, P J, Ward, M E, and Glynn, A A, British fournal of Venereal Diseases, 1971, 47, 448.

${ }^{5}$ Glynn, A A, and Ward, M E, Infection and Immunity, 1970, 2, 162.

${ }^{6}$ Johnston, D W, Holmes, K K, and Gotschlich, E C, fournal of Experimental Medicine, 1976, 143, 741.

' Buchanan, T M, and Arko, R J, fournal of Infectious Diseases, 1977, 135, 879

${ }^{8}$ Kellogg, D S, et al, fournal of Bacteriology, 1968, 96, 596.

${ }^{9}$ Novotny, P, Short, J A, and Walker, P D, fournal of Medical Microbiology, $1975,8,413$.

${ }^{10}$ Buchanan, T M, et al, fournal of Clinical Investigation, 1973, 52, 2896.

11 Tramont, E C, Infection and Immunity, 1976, 14, 593.

${ }^{12}$ Buchanan, T M, Fournal of Experimental Medicine, 1975, 141, 1470

${ }^{13}$ Novotny, P, and Turner, W H, fournal of General Microbiology, 1975, 89, 87.

${ }^{14}$ Richardson, W P, and Sadoff, J, Infection and Immunity, 1977, 15, 663.

${ }_{15} \mathrm{James,}$ J F, and Swanson, J, Fournal of Experimental Medicine, 1977, 145, 1082 .

\section{Mortality and oral contraceptives}

Eight years ago both doctors and their patients were taken unawares by an announcement from the Committee on Safety of Drugs ${ }^{1}$ about oral contraceptives and thromboembolism, and there was both public disquiet and professional outrage. We believe that there should be a more considered response to the two papers from Oxford and the Royal College of General Practitioners published this week in the Lancet. ${ }^{23}$ Essentially their findings extend and confirm earlier work, but they put a higher figure on the mortality rate associated with the use of oral contraceptives. On this occasion advance warning was available, and the Royal Colleges of General Practitioners and Obstetricians and Gynaecologists give advice to doctors at $\mathrm{p} 947$.

The first paper presents fresh data from the long-term study of 46000 women organised by the RCGP. The total of womanyears of observation is now about 200000 and there have been 56 deaths in the pill-users and 45 in the controls. Nevertheless, deaths from circulatory disorders (non-rheumatic heart disease, hypertension, and cerebrovascular disorders) were found to be almost five times as common in women on the pill as in those using other contraceptives. The difference in the two death rates is 20 per 100000 women per year, which represents 1 death each year per 5000 women taking the pillsubstantially larger than most previous estimates of this risk. The second paper reports results from another long-term study organised through the Family Planning Association in Oxford. The 17000 women recruited to the trial have been under observation for nine years. So far there have been 43 deaths; but, while there were nine deaths from cardiovascular causes among the women who were taking the pill at the start of the trial, none occurred in those using a diaphragm or an intrauterine device. In both studies, however, the deaths from cardiovascular disease were concentrated in women aged 35 or more, and there was a strong association with smoking. That there is a dramatic change in the risk of pill-associated coronary thrombosis with age and smoking habit was shown by Mann and Inman ${ }^{4}$ in 1975, and these latest results suggest that the same is true of cerebrovascular disorders and of other forms of heart disease.

What are the practical implications of these latest warnings? The Committee on Safety of Medicines (see p 965) and the two Royal Colleges are agreed that there need be no change in oral contraceptive practice for women aged less than 30though they should be warned of the dangers to health of smoking. Surely the reports underline yet again, if it was needed, the importance of firm action by the Government against smoking-in particular, much wider publicity about its dangers. For teenagers and women in their 20 s the pill will remain the first choice for safe, effective contraception. Such a blanket reassurance can no longer be given to women above the age of 30 , and doctors should be prepared to discuss possible alternative forms of fertility control with patients in this age range. Factors which should be taken into account include the length of use of oral contraceptives, cigarette smoking, and general health, including any evidence of diabetes or hypertension."

As the Royal Colleges' statement emphasises, however, there is no need for women in their 30 s and 40 s taking oral contraceptives to make any immediate, panic change. The risks have not increased: they have simply been recalculated-and the total numbers of deaths on which the calculations are based are small. No longer, however, does it seem reasonable to expect women to take oral contraceptives for virtually their whole reproductive span with no thought given to any alternate strategy. The weight that should be given to convenience, reliability, and safety varies with age and with circumstances, and patients need advice and guidance. For many couples who have completed their families sterilisation of either husband or wife may be preferable to any of the other alternatives.

${ }^{1}$ British Medical fournal, 1969, 4, 755.

2 Beral, V, and Kay, C R, Lancet, 8 October 1977.

${ }^{3}$ Vessey, M P, McPherson, K, and Johnson, B, Lancet, 8 October 1977.

${ }^{-}$Mann, J I, and Inman, W H W, British Medical fournal, 1975, 2, 245.

${ }^{5}$ Mann, J I, et al, British Medical fournal, 1975, 2, 241.

\section{Words}

This week we start a new "filler series" in the Medical Practice section, entitled Words. This will be an occasional series browsing among the origins, uses, and curious aspects of medical terminology. For some time this has been one of the hobbies of Dr Bernard Freedman, who has drafted this series, and we hope that readers will enjoy his discoveries about some present-day terms and ancient beliefs. 